\title{
Topical calcipotriol as a new therapeutic option for the treatment of clear cell acanthoma
}

\author{
Gaetano Scanni ${ }^{1}$
}

Giovanni Pellacani²

\section{DOI: http://dx.doi.org/10.1590/abd1806-4841.20143079}

\begin{abstract}
Although uncommonly diagnosed, clear cell acanthoma represents an original source of speculative interest for dermatologists. Due to its clinical variability, it is often only recognized accidentally after histology. Dermoscopy has improved the reliability of clinical diagnosis of typical clear cell acanthoma thanks to the vascular pinpoint pattern and desquamative, peripheral collarette. Generally, therapy of clear cell acanthoma is oriented towards ablative solutions, such as surgery or cryotherapy. We propose a conservative therapy, based on the application of topical calcipotriol, which has produced complete regression after 2 months and no relapse one year after the end of treatment. A dermatoscope monitored all changes of clear cell acanthoma, showing its utility not only in diagnosis but also in therapeutic follow-up. This new therapeutic approach should support an inflammatory etiology of clear cell acanthoma, although further observations are needed to confirm this.
\end{abstract}

Keywords: Acanthoma; Dermoscopy; Vitamin D

\section{INTRODUCTION}

Clear cell acanthoma (CCA) is a rare, benign epidermal proliferation. ${ }^{1}$ It usually presents as a single dome-shaped, sharply circumscribed, red-brown papule, often localized on the lower extremities of elderly people, although unusual presentations have been reported. ${ }^{2,3}$ Dermoscopy enables a very confident diagnosis in many cases, due to the presence of a very characteristic pattern constituted by widespread pinpoint-like, dotted and/or glomerular vessels, linearly arranged as a string of pearls to create a network-like appearance. ${ }^{4}$

Its exact nosological position is still debated. In fact, it is generally considered to be a benign epidermal neoplasm, although some authors are in favor of describing it as a reactive inflammatory hyperplasia. ${ }^{1,5}$

Many destructive treatment options have been proposed, such as cryotherapy, curettage, and electrocoagulation. However, surgical excision is usually performed, as many cases are misdiagnosed as basal cell or squamous cell carcinomas. ${ }^{2}$

Here we present a case of typical CCA cleared after 2 months' topical treatment with calcipotriol. Clinical and dermoscopic documentation of tumor involution and persistent clearance over one year is shown in this report.

\section{CASE REPORT}

A 78 year old man referred to our Unit due to a solitary, palpable, erythematous, dome-shaped, 8$\mathrm{mm}$ papule on his left leg. Lesion was asymptomatic and was said to have been present since a few months.

No personal or family history of psoriasis was declared. Dermatoscopy showed unequivocal patterns of CCA, i.e., dotted vessels organized as "strings of pearls" and keratinized collarette (Figures 1A and 1B). ${ }^{4,6}$ Clinically and dermoscopically well-defined borders in combination with lesion and patient history reasonably excluded psoriasis.

Since the patient refused all proposed destructive treatments, after informed consent was obtained, an alternative, off-label therapy was performed. Calcipotriol $0.005 \%$ cream was applied twice a day and followed by a two-week dermoscopic digital monitoring period. Therapy was administered for 2 months during which time the patient did not report any local or systemic side effects.

\section{Dermatoscopic follow-up}

Dermatoscopic images were obtained by means of both an immersion non-polarized contact device (Delta 20, Heine) and a polarized light device (DermLite Pro II, 3Gen).?

\footnotetext{
Received on 23.08.2013.

Approved by the Advisory Board and accepted for publication on 28.11.2013.

* Work performed at the Distretto Socio Sanitario - ASL Bari, Bari, Italy.

Financial Support: none

Conflict of Interests: none

Distretto Socio Sanitario - ASL Bari - Bari, Italy.

University of Modena and Reggio Emilia - Modena, Italy.

(C)2014 by Anais Brasileiros de Dermatologia
} 


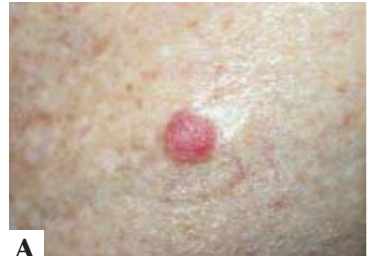

$\mathbf{A}$

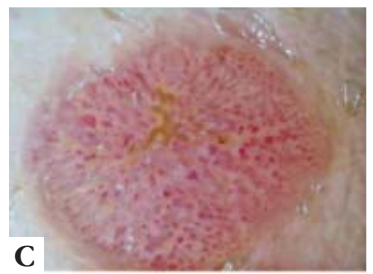

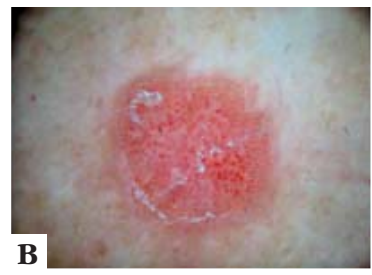

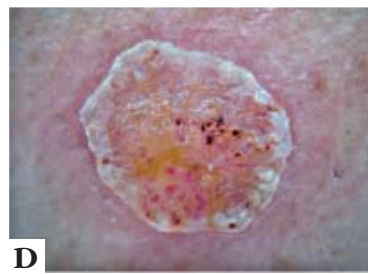

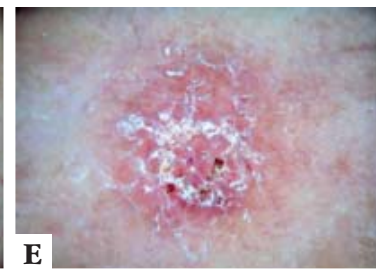
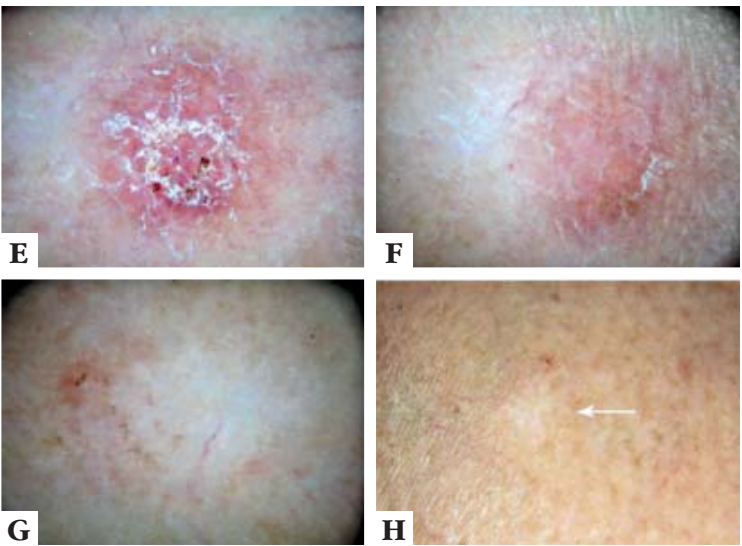

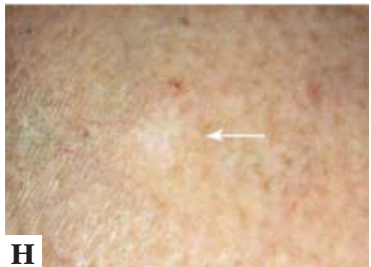

Figure 1: A. Before therapy. Macroscopic aspect of the clear cell acanthoma: solitary, well-defined pink papule of the leg. B. Dermoscopic image showing dotted vessels organized as "strings of pearls" and keratinized collarette (DermLite). C. After 15 days of therapy. Yellowish, irregular, star-shaped area in the center of the lesion (Delta 20).D. After 30 days of therapy. Dermoscopy showing a scaly collarette, central yellow area and persistence of a few dotted vessels (DermLite). E. After 45 days of therapy. Dermoscopy showing a pink to light brown background area, lacking vascular structures and covered with fine white scales (Dermlite). F. After 60 days of therapy. Dermoscopy showing a light brown pigmentation was visible on a slightly pinkish background, with no evident vessels (Dermlite). G. After 12 months without therapy. Dermoscopy showing a slightly hypochromic area (Dermlite). H. Macroscopic aspect exhibits full regression of CCA with only a slightly hypochromic area. Photographic records of all clinical and dermatoscopic inter-stages excluded from this paper due to editorial limits are available at http://www.gaetanoscanni.it/CCA_full_story

-After 15 days of therapy no macroscopic changes were visible. Only a yellowish, irregular, star-shaped area was appreciated in the center of the lesion (Figure 1C).

-After 30 days of therapy a scaly collarette appeared, with persistence of a few dotted vessels. The central yellowish structure became larger and more evident (Figure 1D).

-After 45 days of therapy the lesion was no longer palpable. A pink to light brown background area, lacking vascular structures and covered with fine white scales was appreciated. A few small, brown-red structures, compatible with crusts/microerosion, were detectable (Figure 1E).

-After 60 days of therapy only a light brown pigmentation was visible on a slightly pinkish background, with no evident vessels (Figure 1F). Treatment was interrupted.

-Twelve months after stopping therapy no recurrence appeared, and a slightly hypochromic area was dermoscopically and clinically visible (Figures $1 \mathrm{G}$ and $1 \mathrm{H}$ ).

\section{DISCUSSION}

Elective treatments for CCA are surgical excision or physical ablation with liquid nitrogen or $\mathrm{CO}_{2}$ laser. ${ }^{2}$ Given the frequent comorbidity with systemic diseases and the psychological aversion to surgery, a conservative approach answers better to the needs of older patients and should be considered due to the lower risk of side effects. Calcipotriol is officially indicated for the treatment of psoriasis because of its ability to inhibit keratinocytes proliferation and promote their differentiation. CCA shares some histopathologic features with psoriasis, such as acanthosis and hypervascularization, which result in similar dermoscopic and confocal microscopic patterns. ${ }^{89}$ However, CCA is generally considered a benign epidermal neoplasm. ${ }^{1}$ In this study, a dramatic clinically and dermoscopically stable response was achieved through the application of calcipotriol, which mainly acts on the differentiation of keratinocytes, further supporting a reactive hyperplasia of inflammatory origin, which is also suggested by recent immunohistological studies. ${ }^{10}$

This report represents the first case describing a complete and stable regression of CCA after topical calcipotriol treatment. Although this finding needs to be confirmed in larger case series, the rapid and progressive regression documented during the 2month treatment period supports the direct action and efficacy of the drug in this process. $\square$ 


\section{REFERENCES}

1. Degos R, Delort J, Civatte J, Poiares Baptista A. Tumeur epidermique d'aspect particulier: acanthome a cellules claires. Ann Dermatol Syphiligr (Paris). 1962;89:361-71

2. Tempark T, Shwayder T. Clear cell acanthoma. Clin Exp Dermatol. 2012;37:831-7.

3. Veiga RR, Barros RS, Santos JE, Abreu Junior JM, Bittencourt Mde J, Miranda MF. Clear cell acanthoma of the areola and nipple: clinical, histopathological, and immunohistochemical features of two Brazilian cases. An Bras Dermatol. 2013;88:84-9.

4. Francesco Lacarrubba, Rocco De Pasquale, Giuseppe Micali. Videodermatoscopy improves the clinical diagnostic accuracy of multiple clear cell acanthoma. Eur J Dermatol. 2003;13:596-8.

5. García-Gavín J, González-Vilas D, Montero I, Rodríguez-Pazos L, Pereiro MM, Toribio J. Disseminated Eruptive Clear cell acanthoma with spontaneous regression: further evidence of an inflammatory origin? Am J Dermatopathol. 2011;33:599-602.

6. Zalaudek I, Kreusch J, Giacomel J, Ferrara G, Catricalà C, Argenziano G. How to diagnose nonpigmented skin tumors: a review of vascular structures seen with dermoscopy: part II. Nonmelanocytic skin tumors. J Am Acad Dermatol. 2010;63:377-86.

7. Pellacani G, Seidenari S. Comparison between morphological parameters in pigmented skin lesion images acquired by means of epiluminescence surface microscopy and polarized-light videomicroscopy. Clin Dermatol. 2002;20:222-7.

8. Bugatti L, Filosa G, Broganelli P, Tomasini C. Psoriasis-like dermoscopic pattern of clear cell acanthoma. J Eur Acad Dermatol Venereol. 2003;17:452-5.

9. Ardigo M, Buffon RB, Scope A, Cota C, Buccini P, Berardesca E, et al. Comparing in vivo reflectance confocal microscopy, dermoscopy, and histology of clear-cell acanthoma. Dermatol Surg. 2009;35:952-9.

10. Yamasaki K, Hatamochi A, Shinkai H, Manabe T. Clear cell acanthoma developing in epidermal nevus. J Dermatol. 1997;24:601-5.

\author{
MAILING ADDRESS: \\ Gaetano Scanni \\ Dermatological Unit, DSS6 ASL Bari \\ Via Nicola Cacudi 31 \\ 70123 - Bari - Italy \\ E-mail: gaetano.scanni@alice.it
}

How to cite this article: Scanni G, Pellacani G. Topical calcipotriol as a new therapeutic option for the treatment of clear cell acanthoma. An Bras Dermatol. 2014;89(5):803-5. 